NCBI Bookshelf. A service of the National Library of Medicine, National Institutes of Health.

Haggett A. A History of Male Psychological Disorders in Britain, 1945-1980. Basingstoke (UK): Palgrave Macmillan; 2015.

\title{
Chapter 1 Psychological Illness and General Practice
}

\section{Introduction}

At a meeting of the Royal Society of Medicine in November 1958, the psychiatrist Michael Shepherd and a group of colleagues observed that most of the previous work on the epidemiological aspects of mental disorder had been focused on institutionalised patients where the population had been 'conveniently circumscribed for the purposes of investigation'. Research, therefore, had been concerned predominantly with major psychiatric disorder. In order to obtain further knowledge about mental illness, Shepherd argued that there was a need for systematic study of the minor psychiatric disorders and their prevalence in the community. Shepherd, a well-respected Professor of Psychiatry, established the General Practice Research Unit at the Institute of Psychiatry in London during the late 1950s. The aim of this unit was to study, by epidemiological methods, 'the causes, nature, extent and distribution of extra-mural mental disorder in the setting of general practice, where, under the conditions of the British National Health Service, information is obtainable about the health of the bulk of the population'. In stating this aim, Shepherd and his colleagues were articulating a view widely expressed by those working in general practice during the post-war period: that family doctors fulfilled a unique role in medicine and should be more widely involved in epidemiological research. The proposal offered general practice the opportunity to gain professional status within medicine, for, as David Hannay has pointed out, at mid-twentieth century, it was viewed as less prestigious than other specialisms and those who opted for it were 'considered to be less able or to have fallen off the specialist ladder'. On the one hand, therefore, moves to promote research in general practice could be seen as one of a number of measures put in place to establish the field as a discipline in its own right - measures that also included the founding of the College of General Practitioners in 1952, the development of vocational training and the evolution of departments of general practice. ${ }^{-}$On the other hand, the work undertaken and records held by family doctors did indeed provide unique insights into patient populations and offer opportunities for research into the incidence of a wide range of diseases, prescribing patterns and clinical decision-making processes.

In an attempt to further my understanding of male psychological illness, I focus on general practice in this first chapter, in part because of the proliferation of research studies that emerged from primary care on mental illness during the period. Combined with the personal recollections of doctors working in practice from the 1950 s to the 1980s, these studies provided me with rich material. Although it is the case that much male mental illness remained undetected in the community, as we shall see, a significant amount of male psychological and psychosomatic illness presented in primary care. The local doctor's surgery also provided a space within which much 'family illness' emerged that was often connected to sick men who were reluctant to seek help for psychological problems or addiction. A good deal of nervous illness in women and children, for example, was related to broader psychosocial problems and difficult interpersonal relationships at home. As this chapter will illustrate, this might go some way towards explaining why women appear to predominate in statistics for mental illness. As Elianne Riska has noted: 'The history of medicine can be perceived as the tale of the rise and fall of medical discourses that have provided a lens through which the physician has constructed disease and its "cause"." Certainly, the story of male psychological illness and its place in general practice, suggests that physicians, as a product of their time and place, played a key role in both reflecting and reinforcing not only the prevailing medical model of psychiatric disorder, but also the dominant model of masculinity that promoted strong, tough providers. Indeed, most physicians at this time were men themselves, and therefore bound by the same nexus of constraints and expectations as their male patients.

\section{Shifting concepts of mental disorder}

Recent academic interest in the history of psychiatric disorders suggests there was a notable shift from an age of 'anxiety', post-Second World War, to a period from the 1970s in which depression emerged as the dominant concept. Allan Horwitz, writing about the American experience, argues that this in part reflected the criticism directed at psychiatry's diagnostic system by critics such as Thomas Szasz and D. L. Rosenhan during the post-war period. ${ }^{6}$ Biological psychiatry required 'specificity' - distinct diagnoses and treatments directed at specific symptoms. The concept of major depressive disorder, as it emerged during the late 1970s, was able to fit this bill more suitably than the large range of ill-defined anxiety disorders, often caused by life's difficulties, which 'lacked the diagnostic specificity needed to give disease entities medical legitimacy'. The increasing emphasis on depression also reflected 
developments in psychopharmacology and, later, the emergence of the new selective serotonin reuptake inhibitors (SSRIs). These proved a 'promising market' in light of concerns about dependency problems with many of the older anxiolytic drugs, in particular the benzodiazepines. The SSRIs claimed to raise levels of serotonin in the brain and harmonised both with the notion of biological specificity and the concept of chemical imbalance - concepts that were to become deeply embedded in both clinical and popular accounts of depression. A point made, not only by Horwitz but also by others such as David Healy, is that the development of new drugs 'shaped the nature of the illness that it was supposedly meant to treat'. ${ }^{8}$ These developments were crystallised with the release of DSM III in 1980, in which the condition 'major depressive disorder' encompassed amorphous and short-lived psychosocial problems as well as serious and chronic depression. Anxiety disorders, in contrast, focused specifically on distinct disorders and individual phobias such as agoraphobia, obsessive-compulsive disorder and post-traumatic stress disorder. ${ }^{9}$ In Britain, the situation differed somewhat as the standard diagnostic tool for mental illness has been the International Classification of Diseases (ICD). Although revision nine, published in 1979, included the condition 'major depressive disorder', 'generalised anxiety states' still featured, in addition to 'distinct phobic disorders'.

Mark Jackson has also drawn attention to the fact that, during the immediate post-Second World War period, society struggled to come to terms with economic depression, the rise in totalitarianism and the fear of atomic warfare, resulting, he argues, in 'an upsurge of anxiety'. 11 Jackson argues, however, that alongside the shift away from the age of anxiety and the move towards a focus on depression in the late 1970s, many commentators turned to the concept of 'stress' to explain a host of clinical conditions and physio-psychological processes. According to Jackson, the concept of stress 'resonated with attempts to come to terms with a rapidly changing world' and stress reactions were more easily quantifiable than anxiety. Motivated by the work undertaken by late nineteenth- and early twentieth-century stress researchers, such as Walter Cannon (1871-1945), Harold Wolff (1898-1962) and Hans Selye (1907-82), and psychosomatic theorists such as Franz Alexander and Helen Flanders Dunbar, increasingly epidemiologists, clinicians and social commentators implicated stressful life events in a range of physical and psychological disorders.

Undoubtedly, these broad intellectual histories do indicate a clear move, metaphorically and clinically, away from anxiety towards a period during the late twentieth and early twenty-first centuries in which depression appeared to emerge as the modern epidemic. However, the remainder of this chapter will illustrate that during the 1950s, 1960s and 1970s, in practice, debates about the diagnosis, classification and cause of mood disorders (and associated somatoform conditions) remained a highly contested area where much variation existed among practitioners.

\section{Studies on psychiatric morbidity}

Surveys of health and sickness have a long history that begins much earlier than the period that is covered by this book. Early studies were motivated by a desire to produce statistical information about the population, amid concerns about the effects of poverty, poor living conditions and social disorder. The first of note is often awarded to Charles Booth for his study of late nineteenth century working class life, Life and Labour of the People (1889 and 1891). However, much earlier, Edwin Chadwick's The Sanitary Condition of the Labouring Population (1842) and the Health of Towns Commission (1843) drew upon interviews and data from Boards of Guardians and general practitioners (GPs). Seebohm Rowntree, in his study of York, Poverty, A Study of Town Life (1901), attempted to move the discipline of sociology from its literary and journalistic affiliates towards a 'social science'. ${ }^{15}$ His study involved the 'intensive' method of interviewing 11,560 families (a total of 46,754 people) in an attempt to discover a true measure of poverty. ${ }^{16}$ Increasingly through the twentieth century, the developing method of sampling enabled surveys to be undertaken more economically.

The hardships and traumas experienced during the Second World War prompted explicit unease about the nation's health. Concerns were particularly focused upon the effects of long hours of work, rationing, blackouts and the general stress of war. ${ }^{17}$ A report undertaken by the Ministry of Health, On the State of the Public Health During Six Years of War (1946) suggested that many outpatient departments and doctors' surgeries were reporting large numbers of people complaining of tiredness and feeling 'rundown'. The summary report for the Ministry of Health in 1944 observed that a range of minor ailments had increased, prompting the General Register Office to put forward plans for an index of morbidity to measure major and minor illness. The result was The Survey of Sickness 1943-1952 (published in 1957), in which a sample of 4,000 people were interviewed about all aspects of their health. ${ }^{18}$ The insights drawn from this research revealed much about broad trends in morbidity. However, when it came to psychological illness, the survey also exposed a range of methodological problems that continued to hamper the pursuits of those working on the epidemiological aspects of mental illness for the next thirty years or more. The authors noted that the fieldwork entailed a range of problems related to the classification of illness. For example, 
where two symptoms were obviously connected, they would be put together; where this was not conclusive, they were noted separately. ${ }^{19}$ This presented particular problems where a physical symptom might have a psychological cause. It was acknowledged that many people might be reticent disclosing the 'exact nature of their illness', and that some respondents retained more objective memories of their condition than others. ${ }^{20}$ As this chapter will suggest, factors like these were to frustrate researchers over the coming years and led the authors to acknowledge that it was debatable whether the study would in fact bring them any 'nearer to a true picture of the state of the health of the community'.

The Survey of Sickness revealed that psychoneuroses and all categories of mental disorder were significantly more common in women. However, with what was to become a defining feature of much of the research to follow, the survey also found that ' ill-defined illness' - sickness that did not fit into clear categories - accounted for a significant amount of morbidity. Men featured in large numbers for ill-defined illness and also for consultations for indigestion and gastrointestinal disturbances. ${ }^{22}$ As will become evident in this book, there is good reason to suggest that many vague diagnoses were related to psychosomatic and psychological illness in men. Motivated by such high levels of neurotic illness, and the concomitant anxieties about the economic cost of sickness absence, from the late 1950s, much research took place in general practice with the aim of understanding more about the causes and prevalence of mental illness. Following the foundation of the College of General Practitioners in 1953, increasingly GPs were prompted to undertake such research themselves. ${ }^{23}$ In 1958, the first national morbidity survey was published, authored by W. P. D. Logan and A. A. Cushion. This was a study of the clinical records from 106 general practices (171 doctors) across England and Wales. Echoing the findings from The Survey of Sickness, the research indicated that psychoneurotic disorders were much more common in females, but that ulcers of the stomach, particularly duodenal ulcers, were more frequently diagnosed in men. ${ }^{24}$ Women also featured with regularity in an interesting category entitled 'Consultations for reasons other than sickness or injury'. ${ }^{25}$ Unfortunately, the study did not elaborate on what precisely these consultations covered; however, the oral histories of general practitioners suggest that women often visited the doctor to disclose personal problems, many of which related to male members of the family.

Through the 1950s and 1960s, many studies appeared in the medical press on the extent of psychological illness in general practice populations. By 1974, nonetheless, commentators conceded that rates of recorded mental illness differed greatly between doctors and between practices. ${ }^{26}$ Anthony Ryle, a GP from London (and son of John Ryle, the renowned Professor of Social Medicine at Oxford University) highlighted the disparities between studies in an article published in the Journal of the College of General Practitioners in 1960. Ryle suggested an approximation could probably be made that 'between 5 and 10 per cent of the population were likely to consult their doctor at least once with symptoms of neurosis', yet some studies estimated that, during a five year period, as many as 40 per cent of patients were at risk. ${ }^{27}$ Ryle put forward a host of explanations that might account for such a wide variation in recorded diagnoses between different investigators. First and foremost of these was 'the absence of any satisfactory criteria of diagnosis'.

\section{Measuring and classifying mental illness}

As community psychiatry increasingly began to replace asylum-based care of individuals with mental illness, psychiatry began to focus on the less severe categories of psychiatric disorder. ${ }^{29}$ As Michael Shepherd pointed out, during the mid-1960s, 'the influx into treatment situations of earlier, milder and more transient cases has helped to bring about a radical alteration of perspective ... In consequence, the epidemiologist . . . has been forced to extend his observations from institutional populations to include the community at large' ${ }^{30}$ Nevertheless, despite increasing research into the nature and causes of moderate to mild psychiatric disorders, no uniform method of diagnosis and classification emerged.

At the heart of controversies on this topic were two fundamental difficulties. The first was the relationship between 'psychotic' and 'neurotic' conditions. R. E. Kendell, Professor of Psychiatry at the University of Edinburgh, remarked in 1976 that the concept of depressive illness 'embraces a wide range of different clinical phenomena and spans the historical distinction between psychosis and neurosis, yet at the same time, the prevailing mood of sadness, helplessness and hopelessness gives it a common core, a unifying theme'. The confusion, he argued, reflected in part a broader philosophical clash between the Meyerian bio-psychosocial approach espoused by Adolf Meyer (18661950), which framed mental illness as 'reaction types' that could be understood within the context of life-situations, and the Kraepelin school, as advanced by Emil Kraepelin (1856-1926) who viewed psychological symptoms as biological, discreet disease entities. Some clinicians were of the view that only one category of organic, depressive illness existed and that symptom severity could be located somewhere along a continuum, while others promoted the idea that there were two or more discreet versions that variously included a range of neurotic and anxiety-related 
symptoms. Nevertheless, a majority of research articles accepted broadly that 'endogenous' or 'psychotic' depression (what we might now diagnose as major depressive disorder) was more likely to embody the 'classical' aspects of melancholic depression: feelings of hopelessness, sleep disturbance, appetite and weight change; whereas, 'exogenous' or 'reactive' depressive states were often typified by feelings of anxiety neurosis and were more likely to be triggered by environmental stress. However, there were many semantic differences between descriptions, with authors variously invoking a host of alternative terms, including: organic depression, cyclic depression, affective disorder, periodic depression and neurotic-depressive reaction. As Kendell pointed out, these semantic differences had produced many misunderstandings in the past and sustained many disputes. The confusion was so widespread and deeply ingrained that, he argued, the profession might be well advised to abandon all terms 'and start afresh'. If any agreement existed at all, it was that the reactive or neurotic class of depression was more difficult to conceptualise.

The second limitation faced by researchers of psychiatric morbidity in general practice was that by restricting psychiatric disorders to the psychotic/neurotic framework, psychosomatic presentations were often excluded from consideration. As Shepherd noted, this often resulted in misleadingly low estimates because many emotionally disturbed patients presented with somatic complaints. A study by John Fry, an early pioneer of research in general practice, for example, found that during the late 1960s, prevalence rates (per thousand) for neurosis among his patients were 238 for men and 528 for women. His conclusion was that the pattern of distribution showed 'a marked preponderance of female patients' and that this conformed broadly with earlier reported figures from the same practice. $^{34}$ Notable in the method and design of his study, however, was the fact that the diagnostic category of neurosis 'did not cover psychosomatic conditions or physical illnesses with a neurotic complaint'. In contrast, research undertaken at another 'average' suburban practice by R. E. Perth found that 39.4 per cent of patients had suffered at least once during five years from some kind of psychosomatic complaint and that 'half the work done during surgery hours was taken up by [these] conditions'. Women, of course, appeared regularly in numbers diagnosed with a wide range of psychosomatic disorders, including headaches, skin disorders and chest pains; however, men predominated in diagnoses of peptic ulcer and epigastric pain - conditions that, according to Perth, were often of psychogenic origin because symptoms disappeared or improved with psychological treatment.

The lack of clarity surrounding the epidemiology and nosology of psychological illness was further compounded by the lack of a reliable screening tool to aid practitioners in making assessments about the mental health of their patients. Until the mid-1970s, the screening tool most often used in research was the Cornell Medical Index (CMI). Originating from Cornell University College, New York in 1949, its purpose was to provide 'an instrument suitable for collecting a large body of pertinent medical and psychiatric data at a minimum of the physician's time'. index contained a total of 195 questions relating to bodily symptoms, past illnesses, family history, behaviour, mood and feeling. Although the index was widely used in general practice research, by the 1970s practitioners had begun to suggest that the questionary scores and practitioners' assessments did not correlate with sufficient accuracy. Indeed, Shepherd noted in 1966 that much of the variation between general practice studies could be accounted for by 'observer factors'. A study of psychiatric outpatients also showed that, when rated with the CMI, many patients would have been 'missed' because their scores fell within the normal range. ${ }^{40}$ A number of other methods existed to aid with diagnosis, including the Hamilton Rating Scale, the Beck Depression Inventory and the Wakefield Self Assessment Depression Inventory. ${ }^{41}$ However, as commentators pointed out, there were significant problems with early measuring scales which were often hampered by a lack of clarity about what was being 'measured': distress or disorder; psychological, emotional or mental wellbeing. ${ }^{42}$ The psychologist and epidemiologist, Barbara Dohrenwend, observed later that these early tools gave general indications of stress, analogous to the measurement of body temperature: elevated scores tell you that something is wrong, but not what is wrong. ${ }^{43}$ High scores might indicate a normal reaction to stressful circumstances, or alternatively, a firm case of neurotic disorder. A further problem was refining the balance between consideration of affective and somatic symptoms, which, as we have seen, often proved an insurmountable obstacle.

Michael Shepherd reputedly felt that designing a screening questionnaire that could apply to everyone was impossible. ${ }^{45}$ However, David Goldberg, a psychologist and psychiatrist who worked closely with Shepherd as a trainee at the Maudsley, developed the General Health Questionnaire (GHQ), which was eventually published as a Maudsley Monograph in 1972. Goldberg's screening instrument was designed to detect the less severe psychiatric disorders - the so-named 'dysthymic states' - and to identify the inability to carry out normal functions. It therefore detected personality disorders and patterns of adjustment associated with 'distress', but not schizophrenia or severe psychotic depression. The main version contained sixty questions, but abbreviated versions were developed for speed of use and consisted of thirty, twenty or twelve items. Although the questionnaire was designed to be completed by 
patients, Goldberg was confident that a high percentage of respondents were 'remarkably frank in admitting symptoms'. ${ }^{46}$ The GHQ has been rated consistently as a leading example of how health measurement methods should be developed, and, in initial studies, scores correlated well with psychological assessments undertaken by a psychiatrist. ${ }^{47}$ However, the questions about symptoms that reflected physical illness relate to pressure or pain in the head, hot or cold spells and 'feeling run down'. Somatic symptoms that were more common in men, such as gastric disorders, might not have been detected by GHQ questions. Furthermore, the physical items were excluded completely from abbreviated formats because they produced a number of ' false-positive' responses.

\section{Somatoform presentations in men}

In his much-cited book, Psychiatric Illness in General Practice (1966), Shepherd cautioned that there were many difficulties involved in supplying general practitioners with a formal definition of a psychiatric case. He suggested that there were a host of psychosomatic symptoms where no organic cause could be found. It was in this area, he argued, that most disagreement on diagnosis could be found. In his study of psychiatric morbidity in general practice undertaken across Greater London, Shepherd formulated a classification system divided into two classes: 'formal psychiatric illness', which included psychosis, neurosis, dementia and personality disorder; and ' psychiatricassociated conditions', which included physical illnesses and symptoms where 'psychological mechanisms' might have played a part in the condition. It is surprising, nonetheless, how many doctors failed to include psychosomatic symptoms in their history-taking, leading Shepherd to suggest that GPs may be under-reporting neurotic illness.

The most common symptoms seen in men who presented in primary care related to the digestive system: dyspepsia, 'epigastric pain' and constipation. Lower back pain and impotence were also viewed as likely to have a psychological aspect. Other symptoms included chest pains and skin rashes - and some physicians felt that there was a psychogenic aspect to asthma. ${ }^{52}$ Gastric symptoms and backache appeared repeatedly in all studies of morbidity in general practice and researchers often noted that men were unlikely to recognise the associations between their symptoms and emotional disorder. W. A. H. ['Arthur'] Watts, a GP from a large surgery in Ibstock, Leicestershire who had developed a keen interest in depressive disorders, noted that these diagnoses were often very difficult. ${ }^{53}$ In a study on depression undertaken among his own patients, he cited numerous case histories. One case provided was a typical example of a man in his early fifties with symptoms related to gastric disorder. When X-ray results returned with negative results, the man eventually admitted that he had been feeling 'morose' and had difficulty sleeping. Asked whether he had ever had thoughts about suicide, he replied that he had, but added: 'I never would have told you had you not asked me. ${ }^{54}$ Watts published widely on depression and anxiety and included a chapter on the clinical pictures of depression in his much-cited book, Depressive Disorders in the Community, published in 1966. In this publication, he provided numerous case histories of male and female patients who presented with unusual physical symptoms related to psychological disorders. One man, a regular attender at an outpatient dermatology clinic, developed symptoms of chronic urticaria. Simultaneously, he appeared to have lost interest in his hobbies and his sex life. The patient was diagnosed with mild depression, and treated with a potent mix of antidepressant and antipsychotic drugs. Watts noted that the man soon improved and that, like many of the mild cases, he was 'relieved' because he had 'felt he was getting neurotic and felt guilty because he was so feeble about things'.

Evidence of male psychological illness presenting as somatic illness was not only visible in published material, but also conspicuous in the notes kept by doctors about their patients and in the oral history testimonies of retired practitioners. There was broad agreement that gastric symptoms provided a 'respectable' reason for visiting the doctor and that men found any underlying psychological symptoms very difficult to talk about. Glen Haden, a retired family doctor from Somerset, recalled that he would try and 'probe' further if he had a suspicion that there was 'something they weren't telling you about', but that 'men were very reluctant to do so. And of course ... they very often presented with gastric or gastro-intestinal symptoms, ${ }^{56}$ Other doctors were less comfortable pursuing a search for emotional causes, reflected perfectly in the testimony of Giles Walden, who recalled: 'I must admit, whether it was just me, but I didn't probe the sort of psychological aspects of it at all . . I think there was resistance [from patients] to any kind of that. You know, you mustn't admit to defeat or inadequacy in any way. ${ }^{57}$ Another GP pointed out that if he began talking to men about psychosomatic symptoms, he had to be 'very careful, because the reaction would be "So you think I'm a hypochondriac!"”. 58 This doctor felt that it was all bound up with 'the macho thing for men ... women will talk about their feelings ... men rarely do that. Even when they're really good friends, they rarely do that'. ${ }^{59}$ Robert Manley, who spent his entire career in general practice in the West Midlands, also confirmed that male anxiety often presented as gastric symptoms. Speaking about patients with digestive disorders, his testimony was typical of those interviewed on the subject: 
I have no doubt that amongst all these people there were a lot who were also worriers ... So, in other words, it was anxiety presenting as gastric symptoms. Similarly, what is now called, well in those days it was called spastic colon, and now irritable bowel, we prescribed DSNT [ double-strength nerve tonic], a mild sedative, because we thought people might be worrying. But, I don't think we really . . . speaking for myself, I don't think we penetrated very far into their psychological disorders. Nor do I think they would be very willing to admit them themselves, because, you know, men don't complain, do they?

During the 1950s and 1960s, John Fry published extensively on the epidemiology and natural history of gastric disorders and many other common medical conditions found in primary care. Fry, a founder member of the College of General Practitioners and a prominent figure in his field, served as a GP in Beckenham, Kent, from 1947 until his retirement in 1991. Fry favoured the use of 'observation' and 'facts and figures' in his research, which he undertook among the patients on his list. In his published research articles on neurosis, Fry was inclined to exclude psychosomatic symptoms from his criteria for diagnosis and hence found that female cases predominated. ${ }^{61}$ In one study on psychoneurosis, he found that females outnumbered males by a rate of 5:1. ${ }^{62}$ Although Fry acknowledged that somatic symptoms might be associated with psychological illness, he did not appear explicitly to address the possible connection between high levels of male gastric disorder, other ill-defined illnesses and psychological distress. By observing symptoms in great detail, Fry focused particularly on 'the natural history' of an illness and warned that physicians should always 'think in terms of organic diseases when making the initial diagnosis'. ${ }^{63}$ He kept meticulous notes from his consultations which were recorded in alphabetical order and included the name and sex of each patient as well as the first and last date of symptoms. He also noted any other extraneous factors that he felt might be relevant to the diagnosis. These entries indicate he saw many male patients with symptoms of psychological distress, often masked by alcohol abuse and somatic symptoms. Gastric disorders were particularly common. A male patient, born in 1916, for example, presented to the surgery regularly with gastric dyspepsia between 1960 and 1966. Fry's notes indicate that the individual was suffering from 'overwork and tension', for which he recommended 'less work' and 'rest'. Another male, born in 1900, presented to the surgery in 1959 with dyspepsia, from which he had apparently suffered 'for years'. The notes suggest that, as a child this patient had endured a 'very disturbed home life' and that he also complained of 'chest pains and anxiety'. The patient was prescribed sodium amytal - a sedative barbiturate, which Fry prescribed with regularity. Similar diagnoses included 'epigastric pain', often concurrent with descriptions of patients as 'unhappy' or 'stressed at work'. Others were noted to be experiencing 'marital discord' . Constipation and other bowel disorders also featured regularly in accounts from family doctors. Graham Hadley, a GP from Birmingham recalled that his 'local proctologist reckoned he had a fair share of uptight, tight-arsed patients who may well have had psychiatric problems as well'.

The quintessential gastric disorder that was thought, at least in part, to be associated with stress or 'distress' was peptic ulcer - a condition that was also significantly more common in men. John Fry developed a keen interest in ulcers and published widely on the topic. From his own patient population, with methods he described as 'simple' and 'based essentially on adequate records over a long period of time', he observed that the condition was much more common in men than women, and was particularly prevalent in males between the ages of thirty and sixty. ${ }^{66}$ Fry suggested that there was no obvious comorbidity in ulcer patients, with the exception of psychoneurosis, which was associated with a number of cases. In circumstances where patients were 'tense', he recommended the use of sedatives, which were useful in helping the sufferer 'cope with their symptoms'. ${ }^{67}$ The role of anxiety in ulcers was also acknowledged by other physicians. The internationally renowned gastroenterologist, Francis Avery Jones (191098), for example, specifically remarked that 'worrying inwardly' and 'bottl[ing] up' were factors that might aggravate the condition or influence its chronicity, emphasising that: 'It is sometimes difficult to appreciate the degree of frustration or resentment that may be hidden. ${ }^{68}$

The medical and social history of peptic ulcers has been well documented and the remit of this chapter is not to repeat existing accounts. However, it is worth briefly revisiting contemporary debates about the causes of peptic ulcer because they reveal much about medical approaches towards organic disease and psychosomatic disorders. The broad trends are well known. Acute gastric ulcers (found in the stomach) were first documented at the beginning of the nineteenth century. Reaching a peak late century, they were more common in young women. This trend changed significantly during the early decades of the twentieth century when female cases declined sharply, to be replaced by rising male mortality from peptic ulcer. ${ }^{69}$ The increase in male numbers could be accounted for largely by cases of duodenal ulcer, which were found in the top section of the intestine as opposed to the stomach. Numbers peaked during the 1950s and began to decline by the 1960s. Complications were a common cause of death and included severe haemorrhage and perforation, the latter requiring urgent surgery. ${ }^{70}$ Early treatments dispensed by the GP were 
limited to antacid medication and patients were usually advised to follow a bland diet and take plenty of bed rest. Serious cases were treated with surgery: gastro-enterostomy and later, vagotomy, which was a procedure to limit acid secretion. $^{71}$ During the 1970s, the Scottish pharmacologist, Sir James Black, introduced cimetidine, a H2 receptor antagonist, which inhibited stomach acid production, allowing ulcers to heal without surgery. This became the mainstay of treatment until the 1980s when the Australian physician, Barry Marshall, discovered that Helicobacter pylori (H pylori) bacteria were the cause of most ulcers.

The discovery of $\mathrm{H}$ pylori revolutionised views on the aetiology and treatment of peptic ulcers, causing what some have described as a 'surge of biological reductionism'. As Susan Levenstein argued recently, this new biomedical model offered the opportunity to move peptic ulcer from a stigmatised 'psychosomatic' cubbyhole into a more dignified 'infectious one'. However, there is still heated debate about the role of psychological factors, and some still maintain that psychological stress probably functions as a cofactor with $\mathrm{H}$ pylori, stimulating the production of gastric acid or promoting behaviour that causes a risk to health. ${ }^{74}$ In formulating a holistic model for peptic ulcers, commentators such as Levenstein have re-energised a biopsychosocial framework endorsed much earlier by physicians, psychosomatic theorists and social researchers who viewed ulcers as one in a long line of 'diseases of civilisation', caused by social change, the rapid pace of industrialisation and the pressures of modern life. ${ }^{75}$ One of the most prominent figures to promote such theories was James Lorimer Halliday (1898-1983) who worked as a Regional Medical Officer with the Scottish Department of Health. Halliday supported a holistic view of medicine and emphasised the role of social and emotional factors in physical disorders. ${ }^{76} \mathrm{He}$ argued that psychosomatic illness was a response to 'noxious psychological factors of environment' and suggested that curative medicine could no longer be contented with the academic question 'what has the patient got?' Instead, he proposed, physicians should ask the more valid question "why did he take ill when he did?" As Rhodri Hayward has recently shown, for Halliday, the morbidity statistics provided by the Scottish Department of Health disclosed not only patterns in the pathologies of claimants, but also revealed 'a complex archaeology of social, cultural and political influences'.

Halliday provided psychoanalytically inflected criticism of a variety of changes in the 'world of the child' and the 'world of the adult' to explain the rise in psychosomatic illness in the mid-twentieth century. He was critical, for example, of the increasing popularity of bottle-feeding and the growing emphasis on child rearing in accordance with medical 'experts', arguing that these moves had resulted in a loss of body contact with the mother. He was also disparaging of the 'preoccupation with bowel training', where, as he put it, 'when the clock struck certain hours, little pots were punctually applied to little botts. ${ }^{79}$ Most critically of all, Halliday noted that, "with the introduction of a relatively abundant supply of household furnishings ... the masses had become possession-conscious'. 'Families were becoming smaller, and houses were increasingly set apart from one another so that playmates were neither so numerous nor available. Then, at the age of four or five, every child was dispatched from the home to the communal nursery or day school, to sit tests and examinations that were anxiety- and panic-causing. ${ }^{81}$ The changes 'in the world of the adult', argued Halliday, had resulted in the drives and impulses of emotional life becoming 'increasingly disturbed, diverted, frustrated or distorted in response to the progressively accelerating changes of the psychosocial environment'. ${ }^{82}$ He noted in particular that man had become increasingly separated from 'mother earth', as urbanisation had resulted in more people being cut off from the 'times and tides of nature'. The growing indifference to cosmic rhythms; the rise of the machine and the spread of unnatural shift-work patterns; and job insecurity had resulted in what Halliday described as 'a progressive increase of inner insecurity'.

Halliday was clearly articulating a range of cultural anxieties. His concern was that the rapidly changing world had resulted in the increase of anxiety, insecurity and helplessness, which were duly implicated in rising numbers of psychosomatic conditions. Evidence of this growing insecurity, he argued, could be found in the expanding popularity of patent medicines and the spread of magazines devoted to such subjects as vigour and personal health. ${ }^{84}$ This association between the civilising process and disease was not new; ${ }^{85}$ however, Halliday's observations on the sexincidence of disease are particularly revealing in what they say about men and masculinity during the period. He argued that the changes in the milieu of adulthood affected the two sexes differently, and, as a consequence, the incidence of most psychosomatic illness was greater in men. He noted that the process of emancipation had resulted in women gaining access to 'many new interests and satisfactions'; yet, it was still socially acceptable for them to express emotion freely. Men, in contrast, were beginning to experience a greater range of anxieties; yet emotional expression for them was largely still viewed as inappropriate.

The notion that gastric disorders were in some way related to the psyche was also not new, but founded upon the work late nineteenth and early twentieth century stress researchers such as Cannon, Selye and Wolff, who all variously examined the troublesome relationship between psychological, biological and social factors in disease. As Herbert 
Weiner has shown, psychosomatic theorists mid-twentieth century espoused a range of different approaches. Helen Flanders Dunbar, the first editor of the American journal Psychosomatic Medicine, proposed that individual personality characteristics tended to be associated with certain conditions. Hypertensive patients, for example, tended to be 'shy and perfectionist', but with 'volcanic eruptions of feeling'. "Franz Alexander, another key figure in the development of the psychosomatic movement, fostered a psychoanalytic model whereby different diseases were thought to be caused by specific unconscious conflicts. Hypertension, in Alexander's view, was thus understood to be the result of the patient's fear of their own 'repressed' aggression.

Peptic ulcer attracted much attention from physicians and commentators who were sympathetic to a holistic approach because it appeared to strike individuals with specific characteristics and often after stressful life events. John Ryle observed in 1932 that duodenal ulcer patients tended to be 'lean and nervous men - often tense and muscular, with brisk mental and physical reactions ... Psychologically, these folk [were] energetic, restless, conscientious, intent on their projects'. The 'male type', noted Ryle, 'spends his energies freely, often bolts his meals, often smokes excessively and generally lacks the aptitude or opportunity for quiet in his life, which falls more frequently to the lot of womankind'. According to Ryle, nervous influences played their part because anxiety and mental conflict seemed to aggravate symptoms. Hence, 'a restless stomach accompanies a restless mind' ${ }^{90}$ Ryle and others argued that the life and occupations of the city were more productive of the disease and that symptoms often followed financial difficulties, family illness or some other distressing event. In a study of peptic ulcers in the decade leading up to the Second World War, the leading social researcher, Richard Titmuss, concurred with Ryle that urban metropolitan areas were implicated in the incidence of peptic ulcers, with numbers in London 'considerably in excess' of the rest of England and Wales. Titmuss drew a correlation with rising mortality from ulcers and the depression of the 1930s, noting that the subsequent economic recovery after the War coincided with a decline in peptic ulcer.

The Second World War caused considerable concern when it was found, almost immediately, that it produced a rise in mortality among military personnel from both gastric and duodenal ulcers, and a more general rise in other gastric disorders. In recent years, these increases have become the focus of historians, who note the shift from 'functional somatic disorders' (such as war neuroses and 'disordered action of the heart' which were commonly seen during the First World War) to a rise in numbers of peptic ulcers during the Second World War. As Edgar Jones has argued, dyspepsia and peptic ulcer dominated the medical agenda of 1940, creating a crisis that threatened to undermine the fighting capability of the British Army. ${ }^{94}$ A nervous disposition and an 'ulcer constitution' were identified as predisposing factors but the military diet and smoking were also thought to play a part. ${ }^{95}$ However, studies soon showed that the incidence of ulcer in the civilian population had also grown rapidly, giving rise to the idea that wartime stress more generally could induce gastric illness. ${ }^{96}$ Ian Miller has argued that theories about the psyche and its role in gastric disorders produced profound changes in treatment and that in the army, the interaction between mind and abdomen began to intrude therapeutic action. Thus, according to Miller, psychological approaches were increasingly given priority over physiological therapy. However, Edgar Jones and Simon Wessely have cautioned against the idea that 'psychiatric models for unexplained symptoms gained ascendancy over more intellectually suspect organic claims', proposing instead that functional somatic disorders do not in fact 'disappear', 'rather, they change their form in response to powerful medical and cultural forces' ${ }^{97}$ Certainly, considerable mystery still surrounds the natural history of peptic ulcer, and no convincing explanation has been found for the rise and fall in cases during the mid-twentieth century. ${ }^{98}$ As Levenstein points out, there has been an ingrained resistance in modern medicine to examining disease in an integrated manner that incorporates both psychological and biomedical elements.

In the decades following the Second World War, family doctors who were sympathetic to a psychosomatic approach did draw an association between psychological distress and physical symptoms, but these doctors were in the minority. The views of those who fostered a holistic approach were sought during a debate that took place during the late 1950s about the place of psychiatry in general practice. A working party of the Council of the College of General Practitioners was appointed in 1956 to study the importance of psychological medicine in primary care, the final version of which was published in the British Medical Journal in $1958 .{ }^{100}$ During this investigation, written evidence was obtained from twenty-seven members of the College who had expressed an interest in psychological medicine. Additionally, details were sought about the subjects taught at medical school in Britain. The correspondence from this investigation suggests that GPs were struggling to deal with a wide range of psychosomatic and neurotic presentations in both sexes. One contributor, a Dr S. I. Abrahams, provided a list of symptoms that were 'difficult to fit in' and which had 'taxed [his] therapeutic resources'. Among the examples provided were the details of a forty-year-old fishmonger who complained of 'pain in his nose, fear of heart disease and cancer etc.' This particular individual also 
suffered from 'guilt feelings over cowardice in action and an act of infidelity'. Abrahams added that the man was of 'obsessional makeup' and that he compensated for his symptoms by over-exercising. Another male patient, aged forty-five, presented with a 'fear of cancer of the throat, with spasm of pharyngeal muscles'. After an in-depth consultation, it appeared that the basic problem was 'a feeling of inadequacy' which emerged whenever decisions had to be made. According to Abrahams, this 'originated in domination by his mother, who was still alive'. ${ }^{101}$ Philip Hopkins, a general practitioner from Hampstead in London, cautioned that 'what might be called gastritis by one doctor becomes acute anxiety state with dyspepsia in the records of another'. Drawing specifically on Logan and Cushion's study, Hopkins specifically highlighted the 'large number of conditions which are in themselves, vague and indefinite'. Had these symptoms, Hopkins argued, 'been found to be due to some physical disease, they would have been put under the appropriate headings'. ${ }^{102}$ Reflecting on his own experiences in practice, Hopkins expounded the importance of psychosomatic symptoms:

A patient might come with a headache, a backache or abdominal pain . . . it mattered little which symptom. If encouraged, the patient would do more than recite a list of symptoms; he would relate them to times, incidents and other factors which were important ... often enough, the presenting symptom acted as a mask, an excuse with which to come to the doctor ... If the opportunity were given, the mask could be dropped. If, on the other hand, the doctor gave the impression that he was not prepared to listen ... but was content to prescribe a tonic or a sedative, then the real trouble remained concealed.

Hopkins was a founder member of the College of General Practitioners, but, most notably, he was the founder and President of the Balint Society and also a founder member of the Psychosomatic Research Society. The Balint Society was named after the influential Hunagarian psychoanalyst, Michael Balint (1896-1970). As the remainder of this chapter will illustrate, physicians who were receptive to and trained in Balint's methods were more likely to be sympathetic to a holistic approach towards their patients. However, as we shall see, despite Balint's significant influence among some GPs, it seems likely that a majority of family doctors formulated their understanding about complex somatoform complaints from within the prevailing reductionist medical model. Doctors' training and attitudes, combined with the harsh day-to-day realities of practice life, resulted very often in what Shepherd described as, at best, a 'tolerant indifference' to the role of psychological factors in disease.

\section{Training and approaches in post-war general practice}

In part reflecting the low status of general practice, doctors entering the field in the years immediately following the introduction of the NHS could expect little or no formal training for the role as a family doctor. ${ }^{\text {D }}$ During the 1950s, some medical undergraduate courses made arrangements for 'attachments' to GP surgeries; however, in only three British medical schools was this made compulsory. By the time the first Chair of General Practice was established in Edinburgh in 1963, there were still only eight medical schools offering all students some experience of general practice. In 1967, the General Medical Council (GMC) recommended that this provision should be expanded, a motion supported by the Undergraduate Education Committee of the Royal College of General Practitioners. However, it was not until 1986 that all British medical schools had departments of general practice. From 1952, following undergraduate qualification, all doctors were required to serve a ' pre-registration' year, during which time they work under provisional registration with the GMC. After this year, fully registered doctors could then undertake specialist postgraduate training in their chosen field. In the early years of the NHS, general practice was not seen as a 'discipline' for postgraduate study: it had no journal, no chair in any university and no academic organisation. ${ }^{108}$ The need for formal postgraduate training had been highlighted in the two influential Cohen Reports of 1948 and 1950. Lord Cohen, who chaired the investigations, stated that post-registration, new recruits should undertake a further three years of specialised training for general practice. However, there were no real developments until the formation of the College of General Practitioners in $1952 .{ }^{110}$ The College began publishing ideas about vocational training in their reports between 1965 and 1967, and, in April 1968, the Royal Commission on Medical Education endorsed the College's findings. Five years of postgraduate training, synonymous with training for other specialties, was recommended - comprising three years of general professional training, followed by two years of vocational training for general practice. Between 1965 and 1985, vocational training schemes of many different kinds were developed across Britain, and, although the Royal Commission's recommendations were not fully implemented, ${ }_{112}$ modified schemes, usually of two years in hospital posts, followed by a year in general practice, were organised. ${ }^{112}$ It was nonetheless not until 1976 that parliament passed the National Health Service Vocational Training Act, requiring three years of mandatory postgraduate training for general practice. 
Given the lack of training for general practice in the broad sense, doctors entering the field during the 1950s and 1960s were unprepared to deal with the kinds of psychological illness that presented in surgery. A working party of the Council of the College was appointed in 1956 to investigate psychological medicine in general practice. Reporting in 1958, it established that there were wide variations between medical schools in the provision of training at ${ }_{114}$ undergraduate level, with some providing regular lectures on psychology and others providing nothing at all. Compulsory attendances at clinical out-patient and in-patient units were similarly variable. The report concluded that the subject should be taught more thoroughly to all undergraduate medical students and that opportunities for postgraduate training in psychological medicine should be available for those with a special interest in the subject. It further noted that 'a grounding in the humanities [was] of value in acquiring maturity and wisdom'.

The lack of preparation for general practice and for dealing with the psychological conditions that presented in primary care, was widely evident in the testimonies of doctors who had experience of practice during the period. As Robert Manley recalled: 'Like everybody else going into general practice in 1961, I was completely untrained for the peculiar skills required . . . although fascinated by the idea of it.' Speaking about the attachment training schemes that existed in some areas at that time, he maintained that 'a lot of these were unsatisfactory . . . they were really exploited as helping hands, and there was virtually no group training or meetings of anything of that sort. ${ }^{116}$ One Professor of General Practice, who developed a well-respected regional postgraduate vocational scheme, roundly summed up the situation:

My generation of doctors ... were appallingly trained in mental and emotional illness, I mean 'destructively' trained, in my humble opinion. We were given some former psychiatric teaching by professors whose patients were all in mental hospitals, who all had florid psychoses, and we'd got absolutely no awareness of the scale of the problem, and we'd got absolutely no training in how to manage it in everyday life. So we came out of our... top universities . ${ }_{117}$ completely naked to deal with this mass of problems that confronted [us]. It was a complete shattering shock.

The prevailing biomedical model within which students were taught at medical school did much to obscure psychological and emotional aspects of disease - a point made regularly by GPs interviewed for this research. For the most part, those who were trained at the top universities noted that the education they received was what they described as 'traditional'. This was particularly so for those who had trained briefly under the renowned psychiatrist, William Sargant (1907-88), at St Thomas' Hospital in London. ${ }^{118}$ An anecdote from one doctor about his early days in clinical training reflected the sentiments of many retired GPs and is worth repeating in its entirety:

[I remember] being told that anatomy dissection started on the second of October, and to report to Anatomy in Room A. And I remember standing outside with a load of other medical students, not knowing what to do. Nobody was there welcoming us. Eventually I think one of us decided, well, we'd better go in, and we went in, and there were the, you know [cadavers], I won't go into the details. And I've always looked back at that as a sort of, kind of, maybe subconscious deliberate desensitisation training . . . to make you tough, make you able to withstand unpleasantness and to, to distance yourself from the patient. And there's nothing more 'distancing' from you than a dead patient that you've spent eighteen months cutting up ... And so, in the mid-1970s, a lot of us felt that we were too distant from our patients.

Another doctor, speaking candidly about his training, maintained that:

[It] wasn't about anything to do with behaviour. It was: people have an illness, you give them a drug, they get better, or you give them a drug and they don't - so you give them another one, or you send them for an operation ... There wasn't an awareness of the other aspects.

The prevailing reductionist approach to medical training did not go unchallenged. Balint was the most influential figure in this respect. He emigrated to England in 1939, and is said to be one of the first in the world to study the possibility of using psychotherapeutic tools in general practice. ${ }_{122}$ After a number of hospital and child-guidance posts, Balint moved to the Tavistock Clinic, London, in 1947. In 1950, with his wife, Enid, he set up a series of seminars for GPs for the discussion of psychological problems in general practice. ${ }^{123}$ The central focus of these seminars was the doctor-patient relationship. Balint believed that the doctor's response to a patient's complaint was as 
important as any drug or treatment administered. He put forward the concept of the 'apostolic function', which, in his words meant that:

Every doctor has a set of fairly firm beliefs as to which illnesses are acceptable and which are not; how much pain, suffering, fears and deprivations a patient should tolerate, and when he has the right to ask for help or relief; how much nuisance the patient is allowed to make of himself etc., . . . These beliefs are hardly ever stated explicitly but are nevertheless very strong. They compel the doctor to do his best to convert all his patients to accept his own standards and to be ill and to get well according to them.

Balint stated that the effects of the apostolic function were far-reaching because they restricted a doctor's freedom: 'certain ways and forms simply do not exist for him' or are 'habitually avoided'. Such limitations, he noted, were determined chiefly by the doctor's personality, training and 'ways of thinking'. The resolution, according to Balint was 'a compromise between the patient's proposition and the doctor's responses'. ${ }^{125}$ Specifically, Balint maintained that doctors had been conditioned by the biomedical model of training: 'The present state of medicine, with its emphasis on organic diagnosis and the corresponding neglect of psychological factors, prompts the doctor to organise illnesses around anatomical, or at least physiological - that is, around some concrete - pathology'. ${ }^{126}$ Consequently, the doctor 'helps' the patient organise their 'illness' around certain symptoms.

Balint's ideas were published in an article in The Lancet in 1955, and developed further in his book, The Doctor, His Patient and the Illness, published in 1957. Some senior figures in the field describe the publication of this book as 'a watershed in the development of general practice', because it provided a theoretical justification for general practice; rejected the 'inferiority' of the generalist; and emphasised the importance of whole-person medicine and holistic care. ${ }^{127}$ However, opinion is divided on the broader influence of Balint's work. In reality, his seminars at the Tavistock Clinic were attended by a very small number of GPs. One of the original group, John Horder, who was instrumental in the development of general practice and President of the College between 1979 and 1982, remarked that 'it was only a small minority of GPs who recognised the potential of Balint's work' and that many regarded those involved with the movement 'with suspicion'. 'It nevertheless, had a profound influence on his own personal approach, because he had never before been taught 'to listen'. He also felt that Balint 'challenged some of the wellestablished beliefs and practices handed down in teaching hospitals, particularly the bias in favour of physical suffering, ${ }^{129}$ Others who were involved with the Balint movement maintain that the small number of doctors who worked with him went on to achieve much wider influence 'as his disciples', through vocational schemes that developed in some areas of the country. ${ }^{130}$ Certainly, many of his ideas are evident in the book, The Future General Practitioner (1972), which is widely extolled as the most important text to be published in the field. ${ }^{131}$ The divide in opinion about Balint's methods and influence is certainly palpable in interviews with retired GPs. Whereas some were sensitive, if not to Balint's original ideas, at least to the notion that practitioners should examine their own attitudes, others were highly critical and completely dismissed his approach. Younger doctors who were more open to alternative ideas often found it impossible to convince older colleagues who were more traditional in their style. Dr Robert Manley, for example, who had read Balint's book and was quite keen to join seminar groups in the early 1970s, recalled: 'I found it difficult to persuade my partners that there should be any change whatsoever in the practice. They were very, very conservative. ${ }^{132}$ Another stated that, although he was aware of the Balint movement, he was 'a bit confused by it all', adding that his practice colleague, 'who was a bit of a hippy', would have been 'more interested in that side of it'.

What is clear from the interviews is that doctors who were sympathetic to a holistic approach were more successful in detecting hidden psychological disorders in patients of both sexes. However, the reverse was true for those whose style of practice was more traditional. As Balint pointed out, for many doctors, psychological symptoms remained 'beyond the professional pale'. ${ }^{134}$ This was particularly significant when it came to diagnosing cases of male psychological or psychosomatic illness because, most doctors, at least until the late 1970s, were also male, and thus both the doctor and the patient found themselves bound by a complex set of medical, cultural and social beliefs which made any discussion of mental illness very difficult. A broader focus on communication and language in doctorpatient consultations did not come until the late 1970s, by which time the general consensus was that most family doctors were not well equipped to deal with psychosomatic disorders and many of the social problems that presented in practice. A study of tape-recorded consultations between patients and doctors during the mid-1970s revealed what was described as 'professionally dreadful' skills (or lack of skills), leading to recommendations for new teaching techniques. ${ }^{135}$ In its conclusion, the report reiterated that doctors' performance should not be measured simply in terms of their diagnostic and prescriptive skills, but also by their ability to create and maintain long-term human 
relationships. Further, it was noted that all doctors were 'both a product and a prisoner of the training system which has produced them'. The prevailing scientific approach had thus resulted in a situation where doctors often accepted the initial offer of symptoms and 'failed to detect a not so obvious psychological and/or psychosomatic disorder'.'

Widely contrasting attitudes are evident in the accounts of doctors who had experience of practice during the period. Nowhere was this more apparent than in views about nervous illness and the status of psychiatry and allied professions. While some physicians took psychological symptoms very seriously, and, despite busy schedules, found time at the end of surgery to re-book patients who needed longer to talk about their problems, others had little time for 'neurotic' presentations and considered them to be a drain on resources. This was undoubtedly in large part due to their training, but in some measure due to the personality of the doctor. H. J. Walton, a psychiatrist at the University of Edinburgh, noted that, among doctors, 'suspicion and scepticism about psychiatry begins early'. Confirming the longheld belief that psychiatry did not carry prestige among medical school departments, he argued that 'many medical students view psychiatrists as emotionally unstable and as confused thinkers' ${ }^{137}$ Walton, in a study of attitudes among medical students, made some interesting observations about their views on psychiatry and mental illness. Evidence from a final-year class suggested that approximately half the class were what he described as 'organically-orientated' and not interested or responsive to psychological illness. A quarter of these did not wish to treat patients with minor psychiatric disorders, while another quarter were uncertain whether they would be prepared to accept cases of psychoneurosis at all. ${ }^{138}$ One student stated explicitly that he '[did] not want to treat psychoneurotic patients in his practice'; another described himself as 'reacting very unfavourably to a large range of patients with psychological components in the illness [and] disturbed that functional illness will form a large part of later practice'.

Although Shepherd, in his study of general practice, found that family doctors were in general tolerant and enlightened, there was nonetheless a significant amount of antipathy towards mental illness. One participating doctor, for example, stated that neurosis was caused by self-indulgence. ${ }^{140}$ Several others refused to participate in the study at all. One maintained that psychiatrists encouraged neurotic patients to avoid their responsibilities; another was of the opinion that all neurotic patients were ungrateful and that nothing could be done for them. ${ }^{141}$ Shepherd found that the degree to which doctors were aware of the social and domestic background of their patients' illnesses varied considerably, and that the majority seemed to accept the phrase 'once a neurotic, always a neurotic'. ${ }^{142}$ Looking back with hindsight over their careers, a number of the doctors who were interviewed for this project were critical of their own attitudes during the early years of practice. Christian Edwards, who was a family doctor in Hampshire, admitted that 'in his youth' he thought that patients with psychiatric symptoms were inadequate: 'Lack of moral fibre, pull yourself together and you'll be alright. But of course you learn that depressives have no way of helping themselves really'. Indeed, the term 'lack of moral fibre' (abbreviated in patients' notes to LMF) emerged more than once in the interviews - a hangover from associations of weakness assigned to soldiers with war neuroses during the Second World War. Richard Stanton, who was very sympathetic himself to the Balint approach, remembered being very critical of a colleague who used to write disparaging comments in his patients' notes:

On one occasion he just wrote, the whole - all his entry was 'witter witter'. And another one he wrote was 'TTHLOAD' $\ldots$ and I asked [the receptionist] 'What's this one?' 'Talks the hind leg off a donkey'. [laughter]. ${ }^{144}$

Another recalled that, just before he retired, a colleague of his pointed out some bad habits he had developed over the years:

I was completely unaware of what I was doing [laughs]. They said, 'Do you realise, you told me [your] technique of getting rid of a patient in the surgery?' If I felt they'd had enough time, apparently I used to move to the edge of my chair, and then sort of get a bit closer, and then I would stand up. And then, you know, usher them out. I was completely unaware that was something I did.

In contrast, some highly sympathetic attitudes were evident. Dr Adams, a GP from the West Country who had trained originally as an anaesthetist in the Forces, described himself as 'very interested in people'. He developed an interest in Gestalt therapy and viewed psychiatric symptoms as having a 'purpose' in that they were often an indication that something was not working well in the patient's life. Adams saw his role as helping raise the patient's awareness of this. His view was that pharmacological treatment was usually unnecessary and just 'papered over the cracks'. Adams was not an ardent follower of Balint and saw him as a kind of 'guru', arguing that a 'map of anything is only ever the map of the person creating it'. His approach instead was ' person-centred' and he maintained firmly that 'the only person who really understands you is yourself'. 
When it came to views about the gendered distribution of psychiatric disorders, many of the general practitioners who practised with a traditional approach were of the opinion that women were biologically predisposed to mental illness. Some of them were willing to admit that this inevitably influenced their own patterns of diagnosis. Robert Manley recalled:

I think there was a gender split. Whether it was in the presentations or whether it was in my mind, I don't know. I mean, the idea of hysteria as a woman's condition was still very much a popular concept in medicine. And menopausal and menstrual changes of mood and so on. Those were current ideas attributed more to psychological than to physiological disorders. And it was very easy to be patronising.

Such views were widely espoused, and evident in the testimony of one very senior and well-respected GP who was emphatic that, 'The female is genetically or biologically more prone to emotional and depressive illnesses.' Urging me to 'read it up', he maintained: 'I don't think it's cultural, and I don't think it's environmental ... I think women get it more, for reasons that I think are not, not yet known. ${ }^{148}$ The same doctor felt that Balint was revolutionary because he demonstrated that symptoms might be a metaphor for 'feelings' - feelings that most often presented in women -'because they were the problem patients, those GPs had brought to him [Balint] . . . a huge skew towards difficult, middle-aged women who hadn't "been sorted", ${ }^{149}$ Indeed, the stereotypical figure of the hysterical or hypochondriac woman widely permeated popular gendered perceptions, with frequent references among doctors to 'bored housewives' and 'fat notes'. One doctor explained, signalling with hand signs that, 'If you took a pile of women's notes "that high" the men's notes would be "down there". 150

Such views must be seen within the context of their time and were formulated upon the longstanding notion that women were dominated by their reproductive systems and prone to irrationality. These ideas remained dominant through the 1950s and 1960s and were still influential into the 1970s. Their influence can be seen in much of the published material on mental illness in the years following the war. Stephen Taylor's report on standards in primary care, Good General Practice, which was submitted to the Cohen Committee, for example, was interspersed with value-laden remarks about 'hysterical' women; 'feckless', 'overwhelmed' and 'sluttish' mothers; and 'suburban housing estates [where] whining anxiety hysterics predominate'. ${ }^{151}$ Even Arthur Watts, whose approach to depressive disorders was generally sympathetic, observed that women's irritability around the time of menstruation left them liable to 'fly off the handle at the least thing'.

Those who were generally open to Balint's ideas, or at least to psychodynamic approaches, often observed that the person who presented at the surgery was not necessarily the patient with a problem. The notion of 'family illness' became an important concept during the 1960s and 1970s and became the focus of a number of publications. F. J. A. Huygen's book, Family Medicine: The Medical Life History of Families, published in 1978, was probably the most well-known of these and was described as influential by several general practitioners in interviews. Huygen was a GP from Holland who used his practice population to observe the long-term physical and psychological health of families. From these observations, he formulated a theory of family dynamics. Using the comprehensive data he had collected from patients alongside his own personal knowledge of them, Huygen connected the medical with the social to reveal hidden illness and better understand unexplained symptoms. His case histories are interspersed with examples of female patients attending with symptoms that were due to problems with male relatives at home: male relatives who were most likely experiencing psychological pressures of their own. Huygen cited one case, for example, where 'the symptoms of the mother - nervousness, sleep disturbances - could, in every instance be related to family problems'. The woman's husband had begun shift work and had experienced difficulties adapting to it, becoming 'irritable and tense at home'. Huygen noted that the wife developed symptoms, 'which mirrored family interactions'. Similarly, in later years when tensions developed with teenage children, 'the mother translated this into somatic symptoms presented to the doctor'. ${ }^{, 53}$ Roger Lea and John Souton, two doctors practising in the West Country, both mentioned that Huygen's work had been influential. Dr Lea maintained that:

The family is a unit, and any dysfunction in that family would present with the one who found it most easy to get to the doctor, that is the - usually the wife ... and she would bring the children. And therefore, the consulting patterns of men were much lower.

Lea described Huygen's book as 'inspirational' and that it was, for him 'quite helpful to realise that actually, patients were part of a unit'. Unsurprisingly, Philip Hopkins, with his openness to psychosomatic presentations, also observed that women might present with illness in response to difficult domestic circumstances. In a chapter on 'stress 
disorders', he gave the example of one woman who had visited him with 'hot flushes, headaches and bouts of depression'. All treatment had failed. Eventually the woman divulged that 'her husband had been coming home drunk at night for some months'. It took Hopkins a little while to persuade her that the symptoms might be related to her husband's behaviour; however, with time there was some improvement and she was better able to cope with her affairs. ${ }^{155}$ However, as Marshall Marinker noted in his contribution to Irvine Loudon's history of general practice, the family-therapy approach did not achieve centrality in Britain where the concept was of greater importance to some general-practice theorists and family-oriented doctors than to most practitioners and their patients.

\section{The realities of practice daily life}

For those entering practice in the late 1950s and the 1960s, the medical and cultural problems of dealing with patients with psychiatric illness were further frustrated by long working hours and the meagre conditions of general practice. A survey of general practice undertaken between 1951 and 1952 by Stephen Hadfield, then Secretary to the British Medical Association (BMA), had identified large variations in practice, but poor facilities and long hours were undoubtedly common themes throughout. Hadfield found that doctors undertook consultations with approximately twenty-five patients in ninety minutes of morning surgery and long rounds of home visits where they would invariably visit five homes in one hour. In many of these homes, he would be expected to see two, three or even four patients when he was expecting to see one - a development for which, according to Hadfield, the NHS was responsible. ${ }^{157}$ Evening home visits were common, even when a rota system with colleagues existed. During times of epidemics, high pressure continued for weeks at a time. ${ }^{158}$ Added to these challenges were administrative duties of paperwork, mail and dealing with large volumes of advertising matter distributed by pharmaceutical companies. These findings were reflected most articulately in Richard Moore's memoirs of his family's medical heritage, Leeches to Lasers: Sketches of a Medical Family (2002). Speaking of his own early years as a locum in the 1960s, Moore recalled surgeries with little equipment, no heating and hard benches for patients to wait for consultations. One surgery he attended was a converted stable where 'the straw and hay had been removed, but no further adaptations for its new role seemed to have been made'. ${ }^{160}$ After an education at a teaching hospital with specialist resources, Moore found himself 'wandering in a world of tonics and placebos more reminiscent of the nineteenth than the twentieth centuries'. Eventually settling permanently in Shrewsbury, Moore's surgery was positioned on the first floor of a 500-year-old building, and he ran the practice initially with two partners and the help of only one part-time receptionist. Moore soon realised he would be required quickly to develop working relationships with colleagues, plus the knowledge and skills of management, accounting, budgeting and planning. 'No attention,' he recalled, 'had been paid to such mundane but fundamental matters in preparation for [his] life's work.' ${ }^{162}$ Consultations were 'rushed' and 'communication with patients was not good'. The situation was even worse at the branch surgery where there were no records or facilities 'other than what [they] carried in [their bags]'. ${ }^{163}$ Moore recalled that during the early years, he and his two partners covered all the demands of the practice, 365 days a year. This entailed domiciliary obstetrics (twenty-five to thirty births a year), night and weekend calls, with only one half day off a week. The working day consisted of three surgeries and ten or twelve home visits on most days, plus a surgery on most Saturday mornings. 'This did not seem arduous in the 1960s,' he recalled, 'because such commitments were usual'. ${ }^{164}$ Moore's experiences were consistent with the recollections of GPs who participated in this project and widely evident in contemporary published material. Shepherd, in his study of general practice found that many practitioners in poor, overcrowded urban areas had so much physical sickness to contend with that they were consequently 'less tolerant of neurotic disorders'. 'It is hard to imagine quite how challenging were the circumstances faced by GPs during the period, but they are summed up powerfully by David Morrell, who was the first doctor from an academic department of general practice to become President of the BMA:

My vocational training lasted three days ... the early weeks and months in the consulting room were confused and I was filled with feelings of guilt. The knowledge and skills acquired in hospital just did not seem relevant to many of the problems presented, and when a proper ' hospital-type' patient presented, there was never time to carry out the type of examination which I had learnt ... I was ... simply conscious of my own inadequacies and the constant demand for care.

\section{Reflections}

Looking back over epidemiological studies on mental illness undertaken during the post-war period, the trends seem straightforward: women were at much greater risk of psychological illness and were diagnosed with it at least twice as often as men. However, the material in this chapter has suggested a more complex picture. The Introduction to this 
book opened with the sobering statistic that 75 per cent of suicides are currently among men, suggesting that there is much we do not yet know about male distress. It is important to note that suicide is sometimes a misleading proxy for mental health: the act is not always 'irrational' and there are circumstances in which an individual's wish to die might be entirely understandable - in older people with multiple physical illnesses, for example. ${ }^{167}$ However, it is widely acknowledged that people with mental health problems are at greater risk of suicide. Although overall rates have declined during recent years, and the ratio of male-to-female suicide rates changed over time, male suicide rates have been consistently higher throughout the nineteenth, twentieth and twenty-first centuries. ${ }^{168}$ Research into suicide during the 1950s acknowledged that men outnumbered women, but rarely shed any light on why this might be.

Broad discussions about suicide were framed by the relative values and disadvantages of the two most common research approaches: the study of epidemiological trends and in-depth studies of suicidal rumination and attempted suicide. ${ }^{169}$ Epidemiological studies often focused on comparative data between different regions or in specific areas. Peter Sainsbury's study, Suicide in London (1955), for example, noted higher numbers in the West End and North West areas and lower rates in Southern boroughs and many of the large working class districts. ${ }^{170}$ His research clearly documented higher rates among men, but 'did not extract any particular environmental factor that appeared to determine this differential sex incidence'. ${ }^{171}$ Other studies tested hypotheses relating to a range of variables such as class, age, the loss of a spouse, divorce and isolation. American research indicated that suicide was more common in the lower classes; however, in Britain, there were no specific investigations on class and suicide during the period. In research published much later during the 1990s, the psychiatrist Norman Kreitman, who wrote widely on suicide and depression, argued that suicide was significantly more common among classes IV and V, echoing findings across the Atlantic. ${ }^{2}$ Kreitman and his colleagues suggested that suicide was associated with social deprivation, chronic mental illness and alcohol abuse. Downward social drift and unemployment were also noted to be key factors in suicide - both factors that were more common in the lower social classes.

In contrast, F. A. Whitlock found that suicide was generally more common in the more affluent classes. With specific relation to sex differences, he noted that male suicides were particularly connected with loneliness and isolation, especially in old age, and that males who were vulnerable to suicide appeared also to express themselves in other violent ways. ${ }^{175}$ These key factors were to be developed in more recent debates about the different ways in which men and women express distress. However, Whitlock acknowledged that, at that time, existing research could say very little about the mental health of communities or about the prevalence of mental illness and alcoholism - which, as will be demonstrated in Chapter 3, were closely correlated. Summing up, he concluded that 'any attempt to bracket together the epidemiological findings in male and female suicide will scarcely do justice to the complexity of circumstances that vary according to the age and sex of the patient'. ${ }^{176}$ Psychiatrists and physicians were keen to find ways of preventing suicide by investigating whether those who had succeeded had made earlier attempts and by examining whether or not individuals had been under medical care at the time of their death. Once again, views differed between studies. R. W. Parnell, a research physician, and Ian Skottowe, a psychiatrist, found in 1957 that among 100 suicides from inquest registers between 1949 and 1956, 53 per cent were not under any medical care. Warning signs nonetheless were apparent in the majority and were evident in extracts from witness statements. The fact that individuals seemed to behave 'normally', even though they may have appeared to be in low spirits, often prevented family, friends and doctors from attempting to 'certify as insane' or refer for psychiatric treatment.

In contrast to Parnell and Skottowe's findings, Alan Capstick, a senior medical officer from Cardiff, found that 78 per cent of 881 suicides considered by him had been treated by their doctor for symptoms that were 'probably' related to psychiatric illness. Because so few of these cases (18 per cent) had been referred for psychiatric support, Capstick called for doctors to raise their awareness of symptoms that might indicate suicidal ideation. Unfortunately, Capstick's data was not divided by sex, so it is not possible to gain insight about the gendered presentation of patients' symptoms prior to suicide. C. A. H. Watts included an entire chapter on suicide in his book on depression in the community and discussed many of the same trends as Sainsbury and other researchers. Watts noted the large numbers of men in statistics, but showed that women were more likely to 'attempt' suicide as a gesture - a cry for help. Detecting men who were vulnerable to suicide seemed particularly difficult and Watts urged that GPs had a special responsibility in detecting depression in its early stages: 'By being better diagnosticians, doctors in general medicine and general practice can probably do more to lower the suicide rate than the psychiatrists themselves' ${ }^{178}$ Indeed, other GPs often remarked that it was difficult to pre-empt suicides, illustrated in the poignant recollections of Jeremy Barrington who remembered a male patient he had treated for depression following a bereavement. After some time, he appeared to improve and presented at the surgery one day in good spirits. The patient told the doctor that he planned to visit his sister to help with her garden: 'He said he was better . . f felt better'; however, 'he went to stay with his sister, dug her 
potatoes, bagged them up and hanged himself in the shed.' Barrington felt that the brief psychological improvement had been because 'he had decided he knew what he wanted to do'.

By the late 1960s social psychologists, sociologists and epidemiologists were beginning to draw attention to the different ways in which men and women might express anguish and distress. These concerns should be seen as one dimension of broader concerns about the health consequences of life stress, social inequality and modern working life. As other authors have pointed out, such anxieties should be seen as a product of a specific historical moment, driven in part by a desire to challenge political structures, and to address contemporary concerns about poverty, crime and warfare. ${ }^{80}$ Debates were politicised between those who viewed the causes of psychological and psychosomatic disorders as related to environmental factors such as social and economic inequality, and those who promoted the theory of individual constitutional vulnerability. Ultimately, western countries, working within an increasingly biological medical model of mental illness and armed with the availability of new psychotropic drugs, tended to move towards a strategy that encouraged physicians and politicians to treat individuals rather than dealing with deep-seated social problems.

The feminist movement motivated some of the psychological and sociological research undertaken during the 1970s. ${ }^{182}$ Many investigations that took place during this period suggested that women were more vulnerable to depression due to the role they fulfilled in society. An influential figure in this respect was the sociologist, George W. Brown, who published widely on depression and gender. As the title suggests, his study, Social Origins of Depression: A Study of Psychiatric Disorder in Women, co-written with Tirril Harris in 1978, proposed unequivocally that social circumstances and life-difficulties unique to the female role, caused depression in women, and in particular for working-class women. ${ }^{183}$ In his later work, he argued that serious or traumatic life events were experienced differently by men and women, and that women were especially vulnerable to depression in reaction to stressful events that had greater 'role salience' for them. By role salience, Brown was referring to the idea that women would identify most acutely with events that involved their children and home, and were likely to hold themselves as responsible for crises in these spheres. ${ }^{184}$ Other scholars put forward valid criticisms of Brown's work, criticising the methodology employed in his earlier work and the conceptual definition of the social variables involved in their analysis. Brown's earlier work could certainly not claim to be entirely representative since it excluded men altogether. The authors designed their 1979 study upon the somewhat sweeping assumption that 'women probably suffer from depression more than men', and that 'they were more likely to be at home and thus available for interview during the day'. ${ }^{186}$ His later work was based on self-reported depression, thereby relying upon men being honest about their emotional states. As this book has suggested, this methodological problem has proved difficult to overcome. Additionally, Brown and his colleagues excluded the presentation of somatic symptoms from their analysis.

Walter Gove's authoritative contribution to debates on gender and mental illness suggested that the difficulties associated with the domestic role caused married women in particular to be vulnerable to psychiatric symptoms and that this explained why women were diagnosed with mental illness more often than men. ${ }^{188}$ The American psychiatrist, Bruce Dohrenwend and his wife Barbara, challenged Gove's theories by arguing that psychological disorders were greater in the lowest social classes and thus related to the stress of their particular environment. ${ }^{189}$ In their work on sex differences in psychological disorders, the Dohrenwends proposed instead that new research methodologies introduced since the Second World War accounted for larger numbers of women in statistics. Their thesis was that pre-war studies were more likely to rely on criminal records, recorded cases of antisocial behaviour and data on alcohol and drug abuse - all categories that were less likely to expose female cases. Post-war, they maintained, investigations focused on interviews with respondents and screening tools such as the Cornell Medical Index. These methods, they argued, concentrated on symptoms of depression and anxiety, indicative of neurosis, and therefore it was 'not surprising that scores on such measures [were] generally higher for women than men'. 190 Dohrenwends concluded that the impression that women were more likely to experience psychological symptoms was 'a function of changes in concepts and methods for what constitutes a psychiatric case'.

In Britain, Monica Brisco, a psychiatrist from the Institute of Psychiatry, also contended that Gove's research did not stand up to careful examination, arguing that, among researchers, there was no consensus about which sex actually experienced greater strain. ${ }^{192}$ Brisco extended her analysis over a ten-year period from the late 1970 s to include a number of important factors associated with gender and psychological disorders. Firstly, her research suggested that women were able to identify 'feeling states' more effectively than men. Secondly, she maintained that women were able to 'show rather more feelings, particularly those of an unpleasant nature than men'; they were thus more likely to seek the advice of a doctor for emotional support. ${ }^{193}$ Thirdly, Brisco's research suggested that men avoided admitting 
negative feelings and found facing up to symptoms of anxiety as "stigmatising'. were aware that women felt more comfortable discussing psychological problems and that this might, in turn, affect their response. ${ }^{195}$ Unable to resolve the polarised debates about nature and nurture, Brisco argued that the relationship between them was far from simple. She nonetheless concluded from her own research that girls were socialised to express feelings more openly than boys, which resulted in a greater awareness of feeling states and, hence, a greater need for emotional support. As one of the potential sources of support was the general practitioner, it was therefore, according to Brisco, not surprising that more women were diagnosed more frequently with psychological problems. Other authors noted more broadly that the 'ethic of health is masculine' and that therefore men looked upon illness 'as a feminine characteristic to be shunned'. Echoing the findings from general practice in this chapter, by the 1980s, observers began to identify that men 'kept depression to themselves' by concealing or camouflaging it. ${ }^{198}$ Because the socialisation into manhood accentuated achievement, competence and success; toughness, confidence and selfreliance, for many men, psychological illness became 'a private experience, unshared with others'.

Whereas femininity had long been associated with emotionality and irrationality, normative masculinity was constructed as 'a man who was in control, both of his inner self and his external environment'. ${ }^{200}$ However, 'masculinity' did not entirely circumvent the medical gaze, for it instead became the focus of medical and psychological studies into coronary heart disease during the late 1950s. Two American cardiologists, Meyer Friedman and Ray Rosenman put forward the concept of the 'Type A personality' during the late 1950s. Type A personalities were defined as being ambitious and highly driven individuals who were often impatient, excessively organised and anxious, leading, according to Friedman and Rosenman, to raised serum cholesterol and an increased vulnerability to coronary heart disease. Type B behaviour personalities exhibited converse behaviour patterns. Type A became a powerful concept through the 1970s and 1980s and was developed in a book for a lay audience Type A Behaviour and your Heart, published in 1974. As Barbara Ehrenreich has pointed out, with the discovery of the Type A personality, cardiologists had not found the elusive molecular 'cause' of coronary heart disease, but instead a unique category of personality that existed without reference to any known categories of psychological disorder. ${ }^{201}$ Thus, the characteristics that prevented men from expressing emotion and seeking help for psychological symptoms were medicalised and recast as a health hazard for men. As Riska observes, the concept of Type A personality led to a realisation that the conformity to a narrow definition of masculinity could be lethal for men. When middle-class breadwinners conformed to the moral values of traditional masculinity, they got a medical label for their pursuit. Unlike women, however, for whom the medicalisation of femininity was usually psychological - for men the cost was entirely physical.

\section{Footnotes}

1 Shepherd Michael, Fisher Michael, Stein Lilli, Kessel WIN. Psychiatric morbidity in an urban group practice. Proceedings of the Royal Society of Medicine. 1959;52:269-274. on 265. [PMC free article: PMC1870622] [PubMed: 13645655]

2 Wilkinson Greg. The General Practice Research Unit at the Institute of Psychiatry. Psychological Medicine. 1989;19:787-790. on 787. [PubMed: 2798647]

3 Hannay David. Undergraduate medical education and general practice. In: Loudon Irvine, Horder John, Webster Charles, editors. General Practice under the National Health Service 1948-1997. Oxford: Oxford University Press; 1998. pp. 165-181. on p. 167.

4 Howe John. Research in general practice: Perspectives and themes. In: Loudon Irvine, Horder John, Webster Charles, editors. General Practice Under the National Health Service 1948-1997. Oxford: Oxford University Press; 1998. pp. 146-164. on p. 147.

5 Riska Elianne. The rise and fall of Type A man. Social Science and Medicine. 2000;51:1665-1674. on 1665. [PubMed: 11072886]

6 Horwitz Allan V. How an age of anxiety became an age of depression. The Milbank Quarterly. 2010;88(1):112-138. on 120. [PMC free article: PMC2888013] [PubMed: 20377760]

7 Horwitz. How an age of anxiety. :119. [PMC free article: PMC2888013] [PubMed: 20377760]

8 Horwitz. How an age of anxiety. :130. [PMC free article: PMC2888013] [PubMed: 20377760] See also Healy David. The Antidepressant Era. Cambridge, MA: Harvard University Press; 1997. and Healy David. Let Them Eat Prozac: The Unhealthy Relationship between the Pharmaceutical Industry and Depression. New York: New York University Press; 2004. See also Callahan Christopher, Berrios German E. Reinventing Depression: A History of the Treatment of Depression in Primary Care 1940-2004. Oxford: Oxford University Press; 2005. For an account of anxiety in the preceding period, see Tone Andrea. The Age of Anxiety: A History of America’s Turbulent Affair with Tranquilizers. New York: Basic Books; 2009. 
9 Horwitz. How an age of anxiety. :126. [PMC free article: PMC2888013] [PubMed: 20377760]

10 See the International Classification of Diseases and Related Health Problems, Revision 9 (WHO, 1979), codes 296. 2-296.4 and 3001. Controversy still surrounds the differences between the current DSM V and the ICD-10 (currently under revision). Not only do diagnostic criteria differ between the two, but there is also disagreement about the values and disadvantages of the 'prototype' matching approach favoured by the ICD and the operational or 'defining features', approach favoured by DSM. See Maj Mario. Psychiatric diagnosis: Pros and cons of prototypes vs. operational criteria. World Psychiatry. 2011;10:81-82. [PMC free article: PMC3104873] [PubMed: 21633674] and First Michael. Harmonisation of ICD-11 and DSM - V: Opportunities and challenges. British Journal of Psychiatry. 2009;195:382-390. [PubMed: 19880924]

11 Jackson Mark. The Age of Stress: Science and the Search for Stability. Oxford: Oxford University Press; 2013. p. 141. See also Tone's Age of Anxiety. Tone describes the new chapter in what W. H. Auden had declared the 'Age of Anxiety', in which post-war America became 'suffused with atomic anxiety', pp. 93-4. The age of anxiety and the emergence of the concept of 'stress' is also discussed at length in Hayward Rhodri. The Transformation of the Psyche in British Primary Care 1880-1970. London, Bloomsbury: 2014. Chapter 3.

12 Jackson. The Age of Stress. : 146 .

13 See Jackson. The Age of Stress. :160. For Alexander and Dunbar, see Weiner H. The concept of psychosomatic medicine. In: Wallace ER IV, Gack J, editors. History of Psychiatry and Medical Psychology. New York: Springer; 2008. pp. 485-516.

14 Yeo Eileen Janes. The social survey in social perspective. In: Bulmer Martin, Bales Kevin, Sklar Kathryn Kish, editors. The Social Survey in Historical Perspective 1880-1940. Cambridge: Cambridge University Press; 2011. pp. 49-65. on p. 49.

15 Harrison Brian. Oxford Dictionary of National Biography. Oxford University Press; 2004. [accessed 12 October 2014]. Rowntree, (Benjamin) Seebohm (1871-1954) online edn, January 2008 http://0-www.oxforddnb.com.lib.exeter.ac.uk/view/article/35856.

16 Rowntree Seebohm. Poverty: A Study of Town Life. 1908 edition. London: Macmillan and Co; pp. vii-viii.

17 Logan WPD, Brooke Eileen M. The Survey of Sickness 1943-1952: Studies on Medical and Population Subjects No. 12. London: HMSO; 1957. p. 11.

18 Logan, Brooke The Survey of Sickness. :11.

19 Logan, Brooke The Survey of Sickness. :22.

20 Logan, Brooke The Survey of Sickness. :22, 26.

21 Logan, Brooke The Survey of Sickness. :26. For comparable studies in the USA, see Callahan, Berrios Reinventing Depression. :3031.

22 Logan, Brooke The Survey of Sickness. :52, 54.

23 Shepherd Michael. Psychiatric Illness in General Practice. Second Edition. Oxford: Oxford University Press; 1981. p. 11.

24 Logan WPD, Cushion AA. General Register Office Studies on Medical and Population Subjects, No. 14, Morbidity Statistics from General Practice, Volume 1. London: HMSO; 1958. p. 34.

25 Logan, Cushion Morbidity Statistics from General Practice, Volume 1. :38.

26 Bransby ER. The extent of mental illness in England and Wales. Health Trends. 1974;6:56-59. on 57.

27 Ryle A. The neuroses in a general practice population. Journal of the College of General Practitioners. 1960;3:313-328. on 315. [PMC free article: PMC1903061] [PubMed: 19790349] See also Perth RE. Psychosomatic problems in general practice. Journal of the College of General Practitioners, Research Newsletter. 1957;4:295-331. [PMC free article: PMC2239276] [PubMed: 19791294] Perth suggested that 40 per cent of the population were at risk.

28 Ryle. The extent of mental illness. :313.

29 The shift from asylum-based care to community treatment has been well documented. See, for example, Scull Andrew. Decarceration; Community Treatment and the Deviant - a Radical View. Cambridge: Polity; 1994. ; Shorter Edward. A History of Psychiatry: From the Era of the Asylum to the Age of Prozac. New York: John Wiley; 1997. ; and also covered in Haggett Ali. Desperate Housewives: Neuroses and the Domestic Environment 1945-1970. London: Pickering and Chatto; 2012.

30 Shepherd. Psychiatric Illness in General Practice. :4. 
31 Kendell RE. The classification of depressions: A review of contemporary confusion. British Journal of Psychiatry. 1976;129:15-28. on 15. [PubMed: 938800]

32 Kendell. The classification of depressions. :17-18.

33 Shepherd. Psychiatric Illness in General Practice. : 17.

34 Cooper Brian, Fry John, Kalton Graham. A longitudinal study of psychiatric morbidity in a general practice population. British Journal of Preventive and Social Medicine. 1969;23:210-217. on 212. [PMC free article: PMC1059203] [PubMed: 5355275]

35 Cooper, Fry, Kalton A longitudinal study of psychiatric morbidity. :211. [PMC free article: PMC1059203] [PubMed: 5355275]

36 Perth. Psychosomatic problems in general practice. :311. [PMC free article: PMC2239276] [PubMed: 19791294]

37 Perth. Psychosomatic problems in general practice. :307.

38 Brodman Keeve, Erdmann Albert J, Wolff Harold G. Cornell Medical Index: Health Questionnaire. New York: Cornell University Medical College; 1949. p. 2.

39 Shepherd. Psychiatric Illness in General Practice. : 105.

40 Goldberg DP, Blackwell B. Psychiatric illness in general practice: A detailed study using a new method of case identification. British Medical Journal. 1970 May 27;:439-443. on 439. [PMC free article: PMC1700485] [PubMed: 5420206]

41 For full descriptions of these screening tools, see Goldberg D. The Detection of Psychiatric Illness by Questionnaire. Oxford: Oxford University Press; 1972.

42 McDowell Ian, Newell Claire. Measuring Health: a Guide to Rating Scales and Questionnaires. Oxford: Oxford University Press; 1996. p. 178.

43 Dohrenwend, cited in McDowell, Newell Measuring Health. :178.

44 McDowell, Newell Measuring Health. :185, 178.

45 Interview with Professor Sir Goldberg David. published in Psychiatric Bulletin. 2001;25:315-320.

46 McDowell, Newell Measuring Health. :226.

47 McDowell, Newell Measuring Health. :234. and Goldberg, Blackwell Psychiatric illness. :441.

48 McDowell, Newell Measuring Health. :234.

49 Shepherd, Clare Psychiatric Illness. :26.

50 Shepherd, Clare Psychiatric Illness. :36-37.

51 For case studies, see Shepherd, Clare Psychiatric Illness. :50.

52 See for example Lask Aaron. Asthma: Attitude and Milieu. London: Tavistock; 1966.

53 Watts CAH. The mild endogenous depression. British Medical Journal. 1957 January 5;:4-8. on 4. [PMC free article: PMC1974004] [PubMed: 13374377]

54 Watts. The mild endogenous depression. :5.

55 Watts CAH. Depressive Disorders in the Community. Bristol: John Wright; 1966. pp. 50-51.

56 Interview with Glen Haden..

57 Interview with Giles Walden.

58 Interview with Richard Stanton.

59 Interview with Richard Stanton.

60 Interview with Robert Manley. Double-strength nerve tonic and other treatments are discussed in Chapter 4 of this book.

61 See for example Cooper, Fry, Kalton A longitudinal study of psychiatric morbidity. :210-217. [PMC free article: PMC1059203] [PubMed: 5355275]

62 See Fry John. The psychoneurotic in general practice. Medical World. 1954 June;:657-666. on 661. [PubMed: 13175822] See also Fry 
John. What happened to our neurotic patients? The Practitioner. 1960;185:885-889. [PubMed: 13825466] B FRYC 7-1 Royal College of General Practitioners Archive.

63 Fry John. The management of psychosomatic disorders in general practice. The Practitioner. 1957;177:554-563. on 554. [PubMed: 13370441]

64 BFRY C2-1 John Fry, Research Notes, Peptic Ulcers, C1950-1980, Royal College of General Practitioners Archive.

65 Interview with Graham Hadley.

66 Fry John, Finer David. Peptic ulcer in general practice. British Medical Journal. 1955 July 16;:169-172. on 173, 169. [PMC free article: PMC1980346] [PubMed: 14389716]

67 Fry, Finer Peptic ulcer in general practice. :171.

68 Jones F Avery. Clinical and social problems of peptic ulcer. British Medical Journal. 1957 March 30;:719-723. on 722. [PMC free article: PMC1974737] [PubMed: 13404283]

69 Morris JN, Titmuss Richard M. Epidemiology of peptic ulcer: Vital statistics. Lancet. 1944 December 30;:841-845. on 842.

70 Wellcome Witness to Twentieth Century Medicine. Peptic Ulcer: Rise and Fall. London: Wellcome; 2000. p. i.

71 Wellcome Witness to Twentieth Century Medicine. Peptic Ulcer. :i.

72 Levenstein Susan. Stress and peptic ulcer: Life beyond helicobacter. BMJ. 1998 February 14;316:538-441. on 538. [PMC free article: PMC2665639] [PubMed: 9501720]

73 Levenstein. Stress and peptic ulcer. :539.

74 Levenstein. Stress and peptic ulcer. :538. [PMC free article: PMC2665639] [PubMed: 9501720]

75 For example, Mervyn Susser and Zena Stein put forward a 'cohort theory' of ulcers in which they viewed the rise in numbers as connected to the 'early phase of urbanisation', and the decline as a response to greater social security from the mid-twentieth century. See Susser Mervyn, Stein Zena. Civilisation and peptic ulcer. Lancet. 1962 January 20;:3-7. [PubMed: 13918500]

76 See Halliday James L. The rising incidence of psychosomatic illness. British Medical Journal. 1938 July 2;:11-14. [PMC free article: PMC2209969] [PubMed: 20781562]; Halliday James L. Epidemiology and the psychosomatic affections: A study in social medicine. Lancet. 1946 August 10;:185-189. [PubMed: 20995257]; and Halliday JL. Psychosocial Medicine: A Study of the Sick Society. London: William Heinemann; 1948. For a full account of Halliday's use of national insurance claims as 'psychological documents', see Hayward. The Transformation of the Psyche. Chapter 3, 'Social consciences'.

77 Halliday. The rising incidence of psychosomatic illness. :13, 14.

78 Hayward Rhodri. Enduring emotions: James L. Halliday and the invention of the psychosocial. Isis. 2009;100:827-838. on 835. [PubMed: 20380350]

79 Halliday. Epidemiology and the psychosomatic affections. :187.

80 Halliday. Epidemiology and the psychosomatic affections. :187.

81 Halliday. Epidemiology and the psychosomatic affections. :187.

82 Halliday. Epidemiology and the psychosomatic affections. :188.

83 Halliday. Epidemiology and the psychosomatic affections. :189.

84 Halliday. Epidemiology and the psychosomatic affections. :189.

85 See Porter Roy. Diseases of civilization. In: Bynum WF, Porter R, editors. Companion Encyclopedia of the History of Medicine. London: Routledge; 1993. pp. 585-600.

86 Halliday. Epidemiology and the psychosomatic affections. :189.

87 Weiner H. The concept of psychosomatic medicine. In: Wallace ER IV, Gach J, editors. History of Psychiatry and Medial Pathology. New York: Springer; 2008. pp. 485-516. See also Dunbar H Flanders. Synopsis of Psychosomatic Diagnosis and Treatment. St Lois, MO: C V Mosby Co.; 1948.

88 Weiner. The concept of psychosomatic medicine. :504. See also Alexander F. Psychosomatic Medicine: Its Principles and 
Applications. New York: W. W. Norton and Co.; 1950.

89 Ryle John A. The natural history of duodenal ulcer. Lancet. 1932 February 13;:327-334. on 328.

90 Ryle. The natural history of duodenal ulcer. :329.

91 Davies Daniel T, Wilson AT Macbeth. Observations on the life-history of the chronic peptic ulcer patient. Lancet. 1937 December $11 ;: 1354-1360$. on 1354.

92 Morris JN, Titmuss Richard. Epidemiology of peptic ulcer: Vital statistics. Lancet. 1940 December 30;:841-845. on 845.

93 Morris, Titmuss 'Epidemiology of peptic ulcer: Vital statistics', 841 and Ian Miller, 'Stress and abdominal illness in Britain c. 19391945. Medical History. 2010;54:95-110. on 95. [PMC free article: PMC2793144] [PubMed: 20046266]

94 Jones Edgar. "The gut war": functional somatic disorders in the UK during the Second World War. History of the Human Sciences. 2012;25(5):30-48. on 34. [PMC free article: PMC5130149] [PubMed: 27917025]

95 Jones. "The gut war":35-36.

96 Miller. Stress and abdominal illness. :101.

97 Jones Edgar, Wessely Simon. Hearts, guts and minds: Somatisation in the military from 1900. Journal of Psychosomatic Research. 2004;56:425-429. on 429. [PubMed: 15094027]

98 Jones. "The gut war":33.

99 Levenstein. Stress and peptic ulcer. :539.

100 See 'Psychological medicine in general practice: A report prepared by a working party of the Council of the College of General Practitioners. British Medical Journal. 1958 September 6;:585-590. [PMC free article: PMC2026321] [PubMed: 13572841]

101 ACE G12-2, Psychiatry and the General Practitioner Working Party Papers 1956-58, Royal College of General Practitioners Archive.

102 Hopkins Philip. Psychiatry in general practice. Postgraduate Medical Journal. 1960 May;:323-330. on 325. [PMC free article: PMC2481607] [PubMed: 14403040]

103 Hopkins Philip. The general practitioner and the psychosomatic approach. In: O’Neil Desmond, editor. Modern Trends in Psychosomatic Medicine. London: Butterworths; 1955. pp. 4-28. on p. 4.

104 Shepherd, Clare Psychiatric Illness in General Practice. :33.

105 Hannay David. Undergraduate medical education and general practice. In: Loudon Irvine, Horder John, Webster Charles, editors. General Practice under the National Health Service, 1948-1997. London: Clarenden Press; 1998. pp. 165-181. on p. 167.

106 Hannay. Undergraduate medical education and general practice. :168.

107 Hannay. Undergraduate medical education and general practice. :168.

108 Gray Denis Pereira. Postgraduate training and continuing education. In: Loudon, Horder, Webster, editors. General Practice under the National Health Service, 1948-1997. pp. 182-204. on p. 183.

109 Hall DW. Vocational training for general practice. Health Trends. 1973;5:80-82. on 80.

110 Gray Pereira. Postgraduate training. :185. For developments in general practice within the context of the organisation of the NHS, see Rivett Geoffrey. From Cradle to Grave: Fifty Years of the NHS. London: King's Fund; 1997. pp. 80-92.

111 Gray Pereira. Postgraduate training. :188. and Hall. Vocational training. :80.

112 Hall. Vocational training. :81.

113 Gray Pereira. Postgraduate training. :192

114 Psychological medicine in general practice: A report prepared by the working party of the Council of the College of General Practitioners. British Medical Journal. 1958 September 6;:585-90. on 588. [PMC free article: PMC2026321] [PubMed: 13572841]

115 Psychological medicine in general practice. :589-590. and 588.

116 Interview with Robert Manley.

117 Interview with David Palmer. 
118 A point that emerged in several interviews with doctors who had contact with Sargant - for example, Jeremy Barrington.

119 Interview with Roger Lea.

120 Interview with Richard Stanton.

121 'Michael Balint', Editorial. Journal of the Royal College of General Practitioners. 1972;22:133-135. on 133. [PMC free article: PMC2156624] [PubMed: 4555279]

122 The Tavistock Clinic was founded in London under the leadership of Dr Hugh Crichton-Miller (1877-1959), initially to explore the traumatic effects of First World War shellshock victims. Its vision was extended to provide systematic major psychotherapy on the basis of concepts inspired by psychoanalytic theory, for patients suffering from psychoneuroses and allied disorders. See Dicks H. Fifty Years of the Tavistock Clinic. London: Routledge and Kegan Paul; 1970.

123 Balint Michael. Editorial. :133.

124 Balint Michael. The doctor, his patient and the illness. Lancet. 1955 April 2;:683-688. on 684. [PubMed: 14354967]

125 Balint. The doctor, his patient and the illness. :684.

126 Balint Michael. Psychotherapy and the general practitioner. British Medical Journal. 1957 January 19;:156-158. on 157. [PMC free article: PMC1974113] [PubMed: 13383219]

127 Balint Michael. Editorial. :133-134.

128 Horder John. The first Balint group. British Journal of General Practice. 2001 December;:1038-1039. on 1039. [PMC free article: PMC1314185] [PubMed: 11766865]

129 Horder. The first Balint group. :1039. [PMC free article: PMC1314185] [PubMed: 11766865]

130 Balint Michael. Editorial. :134. This was also the opinion of David Palmer (who became very influential in one regional vocational scheme). See also Marinker Marshall. What is wrong and how we know it: Changing concepts of general practice. In: Loudon, et al., editors. General Practice. pp. 65-91. esp., p. 73.; and Hayward. The Transformation of the Psyche. Chapter 4.

131 The Future General Practitioner: Learning and Teaching. Royal College of General Practitioners; 1972. This textbook illustrates a noticeable shift towards the importance of interpersonal relationships, patient-centred care and the consultation process.

132 Interview with Robert Manley. A point confirmed in Walton HJ. Effect of the doctor's personality on his style of practice. Journal of the Royal College of General Practitioners. 1969;17(82) supplement 3:6-17. on 6. [PMC free article: PMC2635163] [PubMed: 5386662]

133 Interview with Glen Haden.

134 Balint. The doctor, his patient. :685.

135 Byrne Patrick S, Long Barrie EL. Doctors Talking to Patients: A Study of the Verbal Behaviour of General Practitioners Consulting in their Surgeries. London: HMSO; 1976. p. 8.p. 9.

136 Byrne, Long Doctors Talking to Patients. :191.

137 Walton. Effect of the doctor's personality. :8.

138 Walton. Effect of the doctor's personality. :11.

139 Walton. Effect of the doctor's personality. :12. These findings are echoed in Bomford RR. The anxious patient and the worried doctor', papers from a joint conference of the College of General Practitioners and the Society of Psychosomatic Research: 'The problems of stress in general practice' Supplement to the Journal of the College of General Practitioners. 1958;1(2):10-13.

140 Shepherd. Psychiatric Illness in General Practice. :55.

141 Shepherd. Psychiatric Illness in General Practice. :33.

142 Shepherd. Psychiatric Illness in General Practice. :52, 68.

143 Interview with Christian Edwards.

144 Interview with Richard Stanton. 
145 Interview with Giles Walden.

146 Interview with Julian Adams. Gestalt therapy was developed by the Germans, Frederick and Laura Perls, during the 1940s. It focuses particularly on awareness of current circumstances and environment. Gestalt therapy developed in part as a reaction towards psychoanalysis and behaviourism during the mid-twentieth century, which were viewed by some as too deterministic.

147 Interview with Robert Manley.

148 Interview with David Palmer.

149 Interview with David Palmer.

150 Interview with Christian Edwards. Graham Hadley explicitly noted that his wife, who was also a GP and worked with him, ran late with her lists each day because of the 'worried well' - notably, according to Hadley, with 'bored housewives'.

151 Taylor Stephen. Good General Practice: A Report of a Survey by Stephen Taylor, Nufffield Provincial Hospitals Trust. London: Oxford University Press; 1954. See for example pp. 417, 430, 431. Lord Stephen Taylor of Harlow, who was a doctor and former Labour Member of Parliament, became influential in the development of general practice and published regularly about social and political issues that affected health.

152 Watts. Depressive Disorders. : 12 .

153 Huygen FJA. Family Medicine: The Medical Life History of Families. Nijmegen: The Netherlands, Dekker and Ven de Vegt; 1978. p. 11. For a British example of a similar theoretical approach, see Kellner Robert. Family Ill-Health: An Investigation in General Practice. London: Tavistock Publications; 1963.

154 Interviews with Roger Lea and John Souton.

155 Hopkins. The general practitioner and the psychosomatic approach. :11.

156 Marinker. Changing concepts of illness. :80. A more radical critique of the family was of course also put forward by Laing RD, Esterson A. Sanity, Madness and the Family. London: Tavistock; 1964. in which the authors argued that 'the family is the unit of illness: not the individual, but the family', p. 23.

157 Hadfield Stephen J. A field survey of general practice. British Medical Journal. 1953 September 26;:684-706. on 685, 686. [PMC free article: PMC2029776] [PubMed: 13082082]

158 Hadfield. A field survey of general practice. :636.

159 Hadfield. A field survey of general practice. :689.

160 Moore Richard. Leeches to Lasers: Sketches of a Medical Family. Killala, Ireland: Morrigan; 2002. pp. $218-219$.

161 Moore. Leeches to Lasers. :220.

162 Moore. Leeches to Lasers. :220

163 Moore. Leeches to Lasers. :220.

164 Moore. Leeches to Lasers. :223.

165 Shepherd. Psychiatric Illness. :55.

166 Morrell David. Introduction and overview. In: Loudon, et al., editors. General Practice. pp. 1-19. on p. 4.

167 Pilgrim David. Key Concepts in Mental Health. second edition. London: Sage; 2009. p. 176.

168 For figures and analysis of suicide in England and Wales, see Thomas Kyla, Gunnell David. Suicide in England and Wales 18612007: A time-trends analysis. International Journal of Epidemiology. 2010;39:1464-1475. [PubMed: 20519333]

169 Emile Durkheim's classic study. Suicide. London: Routledge; 1955. was cited as a classic epidemiological study.

170 Sainsbury P. Suicide in London, Maudsley Monographs No. 1. London: Chapman and Hall; 1955.

171 Whitlock FA. Suicide in England and Wales 1959-63, Part 2: London. Psychological Medicine. 1973;3:411-420. on 411. [PubMed: 4762220]

172 Kreitman Norman, Carstairs Vera, Duffy John. Association of age and social class with suicide among men in Great Britain. Journal 
of Epidemiology and Community Health. 1991;45:195-202. on 195. [PMC free article: PMC1060757] [PubMed: 1757760]

173 Kreitman, Carstairs, Duffy Association of age and social class with suicide. :199. [PMC free article: PMC1060757] [PubMed: 1757760] Kreitman was director of the Medical Research Council Unit for Epidemiological Psychiatry in Edinburgh, where, from the 1970s, he undertook research into suicide, female depression and alcohol consumption. He coined the term 'parasuicide', a recognition, not acknowledged at the time, that most episodes of self-harm are not attempts at suicide. See Casey Patricia, Obituary, Kreitman Norman. Psychiatric Bulletin. [accessed 5 March 2015]; doi: 10.1192/pb.bp.113.043521.

174 Kreitman, Carstairs, Duffy Association of age and social class with suicide. :199. [PMC free article: PMC1060757] [PubMed: 1757760]

175 Whitlock FA. Suicide in England and Wales 1959-63, Part 1: the county boroughs. Psychological Medicine. 1973;3:350-365. on 361, 362. [PubMed: 4729194]

176 Whitlock. Suicide in England and Wales 1959-63, Part 1. :362.

177 Parnell RW, Skottowe Ian. Towards preventing suicide. Lancet. 1957 January 26;:206-208. [PubMed: 13399175]

178 Watts. Depressive Disorders. :124, 132

179 Interview with Jeremy Barrington.

180 Jackson. The Age of Stress. : 186.

181 Jackson. The Age of Stress. :191. For a full account of these concerns, and research into the social causes of stress and illness see Jackson. The Age of Stress. Chapter 5, 'Coping with stress'. Haggett Ali. Desperate Housewives: Neuroses and the Domestic Environment, 1945-1970. London: Pickering and Chatto; 2012. pp. 86-95.

182 See for example, Chesler Phyillis. Women and Madness. London: Allen Lane; 1974.

183 Brown George W, Harris Tirril. Social Origins of Depression: A Study of Psychiatric Disorder in Women. paperback edition. London: Tavistock; 1979. p. 279.

184 Nazroo James Y, Edwards Angela C, Brown George W. Gender differences in the prevalence of depression: Artefact, alternative disorders, biology or roles? Sociology of Health and Illness. 1998;20(3):312-330. on 324.

185 See Tennant Christopher, Bebbington Paul. The social causation of depression: A critique of the work of Brown and colleagues. Psychological Medicine. 1978;8:565-575. [PubMed: 724870]

186 Brown, Tirril Social Origins of Depression. :279.

187 See Nazroo, Edwards, Brown Gender differences in the prevalence of depression.

188 See Gove Walter. The relationship between sex roles, marital status and mental illness. Social Forces. 1972;51:34-44. For debate about Gove's work, see Haggett. Desperate Housewives. :107-108.

189 Jackson. The Age of Stress. :194.

190 Dohrenwend Bruce P, Dohrenwend Barbara Snell. Sex differences and psychiatric disorders. American Journal of Sociology. 1976;81:1447-1454. on 1452. [PubMed: 1036869]

191 Dohrenwend, Dohrenwend Sex differences and psychiatric disorders. :1452.

192 Brisco Monica. Sex differences in psychological wellbeing. Psychological Medicine, Monograph Supplement, Supplement 1. 1982:1-46. on 6. See also Brisco Monica E. Sex differences in perception of illness and expressed life satisfaction. Psychological Medicine. 1978;8:339-345. [PubMed: 652903]

193 Brisco. Sex differences in psychological wellbeing. :37.

194 Brisco. Sex differences in psychological wellbeing. :38.

195 Brisco Monica E. Why do people go to the doctor? Sex differences in the correlates of GP consultation. Social Science and Medicine. 1987;25(5):507-513. on 511. [PubMed: 3672148]

196 Brisco. Sex differences in psychological wellbeing. :42.

197 Phillips Derek L, Segal Bernard E. Sexual status and psychiatric symptoms. American Sociological Review. 1969;34(1):58-72. on 
60. [PubMed: 5776179]

198 Warren Lynda W. Male intolerance of depression: A review with implications for psychotherapy. Clinical Psychology Review. 1983;3:147-56. on 149 .

199 Warren. Male intolerance of depression. :150.

200 Riska. The rise and fall of Type A man. :1666. [PubMed: 11072886]

201 Ehrenreich Barbara. The Hearts of Men: American Dreams and the Flight from Commitment. New York: Anchor Press/Doubleday; 1984. pp. 82-84.

\section{(C) Ali Haggett 2015.}

The author has asserted his right to be identified as the author of this work in accordance with the Copyright, Designs and Patents Act 1988.

Palgrave Macmillan in the UK is an imprint of Macmillan Publishers Limited, registered in England, company number 785998, of Houndmills, Basingstoke, Hampshire RG21 6XS.

Palgrave Macmillan in the US is a division of St Martin's Press LLC, 175 Fifth Avenue, New York, NY 10010.

Palgrave Macmillan is the global academic imprint of the above companies and has companies and representatives throughout the world.

Palgrave ${ }^{\circledR}$ and Macmillan ${ }^{\circledR}$ are registered trademarks in the United States, the United Kingdom, Europe and other countries.

Except where otherwise noted, this work is licensed under a Creative Commons Attribution 3.o Unported License. To view a copy of this license, visit http://creativecommons.org/licenses/by/3.o/

Monographs, or book chapters, which are outputs of Wellcome Trust funding have been made freely available as part of the Wellcome Trust's open access policy

Bookshelf ID: NBK333545 